\title{
Situación laboral del periodista: campo de estudio en construcción
}

\section{Work Status of Journalists: A Study Field under Construction}

\author{
Carolina García Pino (Colombia) \\ Universidad Francisco de Paula Santander \\ Comunicadora Social. Especialista en Práctica \\ Pedagógica Universitaria. Correo electrónico: \\ garciapinocarolina@gmail.com
}

\author{
Darlin Johanna Ramírez Leiva (Colombia) \\ Universidad Francisco de Paula Santander \\ Estudiante de Comunicación Social. Correo \\ electrónico: dar.ramirez04@gmail.com
}

\section{Resumen \\ El presente artículo hizo una revisión del estado actual de la investigación sobre la situación laboral del periodista y su satisfacción a partir de cincuenta investigaciones similares que abordan}

\section{Joselyn Katherine Osorio Fonseca (Colombia) Universidad Francisco de Paula Santander Estudiante de Comunicación Social joselynosorio04@gmail.com}

\begin{tabular}{|c|c|c|}
\hline $\begin{array}{l}\text { RECIBIDO: } \\
\text { EVALUADO: } \\
\text { ACEPTADO: }\end{array}$ & $\begin{array}{r}30 \text { de abril } 2015 \\
8 \text { de mayo de } 2015 \\
12 \text { de mayo de } 2015\end{array}$ & 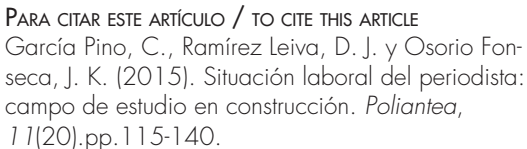 \\
\hline
\end{tabular}


la temática. La información se encuentra organizada de acuerdo con el contexto de ocurrencia de las investigaciones, que inicia en España, continúa América Latina, Colombia, y finaliza en Cúcuta, donde se ha abordado el campo laboral del periodista en los medios de comunicación y las organizaciones no gubernamentales. El propósito del artículo fue conocer el panorama laboral de estos profesionales, así como las perspectivas desde las cuales se ha abordado su estudio.

Palabras clave: comunicador social, situación laboral, medios de comunicación. occurrence context, starting in Spain, continuing in Latin America, Colombia more specifically, and ending in the Colombian city of Cucutá, where this topic is of great importance for local mass media and non-governmental institutions. It is important to mention that the purpose of this revision was to know the work scene of these professionals as well as the perspectives used when studying it.

Keywords: social communicator, work scene, mass media 


\section{Introducción}

Con ánimo de conocer las tendencias de la investigación sobre la situación laboral del comunicador social y hacer una aproximación, el programa de Comunicación Social de la Universidad Francisco de Paula Santander (UFPS) se dio a la tarea de identificar la producción científica sobre el tema, en la que encontró cincuenta documentos, entre los que se cuentan artículos de resultados de investigación, libros de compilación y documentos institucionales sobre la situación de estos profesionales en el mercado laboral.

La intención de conocer el campo de estudios del ejercicio periodístico como profesión inició con la lectura del Mapa de los centros de formación de comunicadores y periodistas en América Latina y el Caribe, elaborado por la Federación Latinoamericana de Facultades de Comunicación Social (Felafacs, 2009), en el que se presenta la situación de los programas de pregrado y posgrado en el área de comunicación y periodismo, así como los retos formativos y laborales, que enfrentan estos profesionales.

El conocimiento del entorno demarca una especial importancia si se espera que los procesos formativos sean coherentes con el contexto nacional e internacional, por lo que estudiar el campo de acción se convirtió en una prioridad e interés para el programa de comunicación social de la UFPS.

Un año más tarde, Gutiérrez (2010) presenta la Situación del comunicador social en el mercado laboral, investigación que logró encuestar 733 profesionales con al menos 2 años de experiencia de toda América del Sur y España, entre ellos relacionistas, publicistas, periodistas y comunicadores, con lo cual se evidencian 
las dificultades del ejercicio profesional y su nivel de satisfacción en las diferentes áreas de la comunicación.

En una revisión más exhaustiva sobre la profesión periodística como campo de investigación, Mellado (2009) realiza un recorrido desde sus inicios en los Estados Unidos, en la década de 1930, donde se elaboraron las primeras encuestas de aplicación nacional, instrumentos que siguen siendo fuente de referencia en este campo de investigación.

Esta autora continúa el recorrido histórico de los estudios periodísticos en España, Alemania e Inglaterra, y encuentra estudios comparativos y de la incursión de la mujer en la labor periodística. Finalmente, realiza un barrido por las investigaciones desarrolladas en América Latina, y da con que durante las décadas de 1960 y 1970 se llevaron a cabo contadas investigaciones sobre el periodista, pero el interés en el área crecería con el tiempo. Y, efectivamente, en la década de 1980, identifica 16 investigaciones en la región, 90 más en la década de 1990 y al menos 100 entre 2000 y 2007.

Con estos dos referentes como punto de partida, se procedió a identificar investigaciones que tocaran el aspecto central de la situación y satisfacción laboral de los comunicadores sociales y periodistas en el mercado. A continuación, estos documentos se han organizado de acuerdo con su contexto de ocurrencia: se inicia con España, continúa en América Latina (Colombia) y finaliza en Cúcuta.

\section{El caso de España}

En la indagación de referencias en el contexto europeo, destacaron las realizadas en España, donde se identificaron siete investigaciones elaboradas entre 2000 y 2012 (tabla 1), que tocan el tema de la situación laboral del periodista en diferentes medios, incluso practicantes de escuelas de periodismo, profesionales y empíricos.

Pero antes de abordar las investigaciones, es preciso destacar la experiencia de la Agencia Nacional de Evaluación de la Calidad y Acreditación (Aneca, s. f.) que produjo el Libro Blanco de la comunicación, en el que incluye un informe sobre la situación de cuarenta programas de pregrado en el área de comunicación en España.

Aneca (s. f.) incluye en su análisis los perfiles del comunicador social en España, que abordan las áreas de 
la comunicación corporativa, el periodismo, las relaciones públicas, la publicidad, entre otras. En su análisis al campo del periodismo, identifica como tendencia la poca demanda por parte del mercado frente a la alta oferta de profesionales en el área. En su mayoría, aquellos que se concentran en la rama del periodismo han logrado su primer empleo a través de las prácticas profesionales y contactos. En el caso español, los salarios suelen ser precarios, lo cual lleva a que exista una gran insatisfacción frente a la profesión, aspecto que se reflejó también en las demás investigaciones consultadas.

Tabla 1. Situación laboral del comunicador en España

\begin{tabular}{|c|c|c|c|}
\hline Autor & Población de estudio & Salario mensual* & Tipo de contratación \\
\hline $\begin{array}{l}\text { Cantalapiedra, } \\
\text { Coca y Bezunarte } \\
\text { (s. f.) }\end{array}$ & 739 periodistas & US\$1100 aproximadamente & $\begin{array}{l}61.2 \% \text { contrato indefinido con } \\
\text { jornada completa }\end{array}$ \\
\hline Calvo (2005) & 66 periodistas digitales & US\$951.30 aproximadamente & $\begin{array}{l}63 \% \text { tiene contrato laboral (se } \\
\text { presentan como contratos indefinido } \\
\text { y por prestación de servicios) } \\
37 \% \text { no cuenta con contrato }\end{array}$ \\
\hline Tejedor (2005) & 39 periodistas digitales & $\begin{array}{l}\text { Entre US\$1057 y US\$1763 } \\
\text { aproximadamente }\end{array}$ & № especifica. \\
\hline Gómez (2009) & 7732 periodistas & US\$1700 aproximadamente & $\begin{array}{l}72.3 \% \text { contrato indefinido } \\
16 \% \text { contrato temporal }\end{array}$ \\
\hline $\begin{array}{l}\text { De la Quintana } \\
\text { (2010) }\end{array}$ & $\begin{array}{l}100 \text { alumnos de último } \\
\text { curso }\end{array}$ & $\begin{array}{l}27 \% \text { no recibe remuneración } \\
48 \% \text { recibe entre US\$265 y US\$ } 423 \\
7 \% \text { recibe entre US\$ } 424 \text { y US\$528 } \\
6 \% \text { recibe entre US\$529 y US\$634 }\end{array}$ & № especifica. \\
\hline Ufarte (2011) & 99 periodistas & $\begin{array}{l}15 \% \text { menos de US\$846 } \\
47 \% \text { entre US\$846 y US\$1586 } \\
15 \% \text { entre US\$1586 y US\$2115 } \\
5 \% \text { más de US\$2115 }\end{array}$ & $\begin{array}{l}\text { Predomina la contratación temporal } \\
\text { Cerca de } 5 \% \text { trabaja sin contrato } \\
\text { alguno } \\
\text { Entre } 9 \% \text { y } 12 \% \text { es freelance }\end{array}$ \\
\hline Sierra (2012) & 87 periodistas & $\begin{array}{l}8 \% \text { menos de US\$634 } \\
41 \% \text { entre US\$1269 y US\$1904 } \\
11 \text { \% más de US\$1904 }\end{array}$ & № especifica. \\
\hline
\end{tabular}

* Los valores indicados en cada investigación fueron convertidos a dólares, según el valor del mercado actual (abril de 2014) para realizar comparaciones y visualizar fácilmente las diferencias entre los distintos resultados.

Fuente: Elaboración propia.

En la tabla 1 puede observarse que las condiciones laborales de los periodistas no han mejorado considerablemente con el paso del tiempo. Se destaca que se mantienen altos porcentajes de profesionales que laboran en una entidad, pero sin ningún tipo de vinculación laboral, lo cual 
los deja en situación de desprotección o en la tarea de asumir los costos de su seguridad laboral. De ahí que García-Ureta, Toral-Madariaga y Murelaga-Ibarra (2012) citen a Fernández Areal (2010) para referirse al periodismo como profesión de muchos retos.

La precariedad laboral lleva a que los periodistas se vean forzados a tener más de un empleo. "Las dinámicas imperantes en el sector empujan a muchos periodistas a trabajar como becarios, freelance, o periodistas a la pieza, cuando no como voluntarios no remunerados" (Ferrández-Ferrer, 2012, p. 7). Además, Calvo (2005) indica que "un $36 \%$ de los encuestados trabaja para más de una empresa" (p. 176). También, en el caso de los periodistas digitales, Tejedor (2005) indica que un tercio de ellos no cuenta con un contrato laboral.

A la precariedad se le suman las diferencias de género en los salarios y los niveles jerárquicos. Gómez (2009) detalla esta realidad e infiere que las mujeres logran menor tiempo de permanencia en una misma organización, así como menos cargos de alto rango, mientras que los hombres ganan más, ocupan en mayor medida posiciones de alto nivel jerárquico en la organización y logran mayores años de experiencia en una misma entidad. Una de las razones por las que las mujeres presentan mayor movilidad está en su búsqueda de labores profesionales, que se adapten, al mismo tiempo, a su papel de madre y esposa. Además de estas diferencias, los profesionales indican que sus condiciones laborales se deterioran debido a las presiones que reciben al realizar su trabajo. Según Cantalapiedra, Coca y Bezunarte (s. f.), $30.8 \%$ de los encuestados reconoció haber recibido presiones políticas, $21.6 \%$ económicas y $39.6 \%$ de otros ámbitos.

Farias y Gómez (2011) y Gómez (2009) llegan a la misma conclusión, al descubrir que $55 \%$ de sus encuestados reconoce recibir presiones de la propia empresa, debido a los intereses de la clase política y de los anunciantes.

Todo esto lleva a que los periodistas estén insatisfechos con su profesión, al ser los salarios bajos, los horarios extensos, los problemas de salud y el bajo reconocimiento las principales causas de insatisfacción (Ufarte, 2011; Calvo, 2005).

\section{América Latina}

En la tabla 2 se presenta una síntesis de las investigaciones de corte 
cuantitativo realizadas en América Latina. En ellas se evidencia, al igual que en el caso español, una predominancia de los bajos salarios y la alta presencia de formas de vinculación laboral por honorarios y sin contrato.

México es el país que peor paga a sus comunicadores, mientras que en Chile se logran los más altos salarios. Sin embargo, es en este último donde se evidencian las mayores diferencias salariales, lo cual lleva a inferir sobre características internas en el ejercicio entre las capitales y las regiones periféricas.

Tabla 2. Situación laboral del comunicador en América Latina

\begin{tabular}{|c|c|c|c|c|}
\hline Autor & País* & $\begin{array}{l}\text { Población de } \\
\text { estudio }\end{array}$ & Salario mensual** & Tipo de contratación \\
\hline $\begin{array}{l}\text { Arroyave y Blanco } \\
(2010)\end{array}$ & América Latina & $\begin{array}{l}36 \text { periodistas de } \\
\text { América Latina }\end{array}$ & Remuneración precaria & № especifica. \\
\hline $\begin{array}{l}\text { Délano, Niklander y } \\
\text { Susacasa (2007) }\end{array}$ & Chile & 141 recién graduados & $\begin{array}{l}6 \% \text { menos de US\$162 } \\
66 \% \text { entre US\$161 y } \\
\text { US\$814 } \\
26 \% \text { entre US\$814 y } \\
\text { US\$1628 }\end{array}$ & $\begin{array}{l}37.7 \% \text { sin contrato } \\
62.3 \% \text { con contrato, de } \\
\text { los cuales: } \\
32.7 \% \text { contrato indefinido, } \\
6.1 \% \text { contrato a término } \\
\text { fijo y } \\
23.6 \% \text { por honorarios }\end{array}$ \\
\hline $\begin{array}{l}\text { Mellado, Parra y Barría } \\
\text { (2009) }\end{array}$ & Chile & 240 profesionales & $\begin{array}{l}44.1 \% \text { entre US\$325.78 y } \\
\text { US\$814.46 }\end{array}$ & $\begin{array}{l}54 \% \text { indefinido } \\
22.8 \% \text { por honorarios } \\
17.8 \% \text { término fijo } \\
5.3 \% \text { sin contrato }\end{array}$ \\
\hline Ayala (2009) & México & 45 periodistas & $\begin{array}{l}40.68 \text { \% percibe US\$889.88 } \\
0 \text { más } \\
62.56 \% \text { más de US\$593.25 }\end{array}$ & № especifica. \\
\hline $\begin{array}{l}\text { Lagos y Cabalín } \\
\text { (2009) }\end{array}$ & Chile & $\begin{array}{l}171 \text { editores y } \\
\text { reporteros }\end{array}$ & $\begin{array}{l}25.6 \% \text { más de US\$2000 } \\
50.6 \% \text { entre US\$ } \$ 800 \text { y } \\
\text { US\$1.800 } \\
23.8 \% \text { entre US\$300 y } \\
\text { US\$750 }\end{array}$ & $\begin{array}{l}77.6 \% \text { indefinido } \\
12.1 \% \text { a término fijo } \\
4.8 \% \text { por honorarios } \\
5.5 \% \text { sin contrato }\end{array}$ \\
\hline $\begin{array}{l}\text { Martínez, Matus y Villar } \\
\text { (2009) }\end{array}$ & México & 158 periodistas & $\begin{array}{l}15 \% \text { gana US\$101 } \\
15 \% \text { entre US\$101 y } \\
\text { US\$302 } \\
26.5 \% \text { gana US\$302 } \\
40 \% \text { más de US\$302 }\end{array}$ & № especifica. \\
\hline $\begin{array}{l}\text { Mellado, Parra y Barría } \\
\text { (2009) }\end{array}$ & Chile & 914 periodistas & No especifica. & $\begin{array}{l}44 \% \text { indefinido } \\
35.3 \% \text { por honorarios } \\
11.7 \% \text { a término fijo } \\
8.8 \% \text { sin contrato }\end{array}$ \\
\hline Burgos y López (2010) & México & 65 profesionales & US\$700.57 aproximadamente & No especifica. \\
\hline
\end{tabular}




\begin{tabular}{|c|c|c|c|c|}
\hline Autor & País* & $\begin{array}{l}\text { Población de } \\
\text { estudio }\end{array}$ & Salario mensual** & Tipo de contratación \\
\hline Gutiérrez (2010) & $\begin{array}{l}\text { América del Sur } \\
\text { y España }\end{array}$ & $\begin{array}{l}733 \text { de toda América } \\
\text { del Sur y España }\end{array}$ & $\begin{array}{l}\text { US\$1033 aproximadamente } \\
\text { US\$500 el sueldo que más } \\
\text { se repite }\end{array}$ & № especifica. \\
\hline $\begin{array}{l}\text { Universidad Autónoma } \\
\text { Metropolitana, } \\
\text { Casa Abierta al } \\
\text { Tiempo y Sistema } \\
\text { de Información de } \\
\text { Estudiantes Egresados y } \\
\text { Empleadores (2010) }\end{array}$ & México & 927 profesionales & $\begin{array}{l}43.89 \% \text { entre US\$65.92 y } \\
\text { US\$329.58 } \\
37.52 \% \text { entre US\$329.65 y } \\
\text { US\$659.17 }\end{array}$ & № especifica. \\
\hline Mellado et al. (2010) & Chile & $\begin{array}{l}94 \% \text { de los periodistas } \\
\text { y educadores que } \\
\text { trabajaban en la capital } \\
\text { del país } \\
97 \% \text { de la Región de } \\
\text { Antofagasta } \\
98 \% \text { de la Región del } \\
\text { Biobío } \\
99 \% \text { de la Región de } \\
\text { la Araucanía }\end{array}$ & № especifica. & $\begin{array}{l}54.8 \% \text { indefinido } \\
28.3 \% \text { a término fiijo } \\
16.9 \% \text { por honorarios o sin } \\
\text { contrato }\end{array}$ \\
\hline $\begin{array}{l}\text { Sánchez Olavarría } \\
\text { (2012a) }\end{array}$ & México & $\begin{array}{l}108 \text { profesionales } \\
\text { titulados }\end{array}$ & $\begin{array}{l}\text { Sueldos entre US\$133.70 y } \\
\text { US\$935.90 }\end{array}$ & № especifica. \\
\hline Vega y Borda (2013) & Bolivia & 100 periodistas & $\begin{array}{l}38 \% \text { entre US\$145 y } \\
\text { US\$291 } \\
25 \% \text { entre US\$291 y } \\
\text { US\$437 } \\
25 \% \text { hasta US\$583 } \\
8 \% \text { más de US\$728 }\end{array}$ & № especifica. \\
\hline $\begin{array}{l}\text { Mellado-Ruiz y Lagos } \\
\text { (2013) }\end{array}$ & Chile & 1979 periodistas & $\begin{array}{l}70 \% \text { menos de US\$2000 } \\
30 \% \text { menos de US\$1000 }\end{array}$ & № especifica \\
\hline
\end{tabular}

* Se han extraído las investigaciones colombianas para desarrollar su análisis más adelante en el texto.

* * Los valores indicados en cada investigación fueron convertidos a dólares, según el valor del mercado actual (abril de 2014) para realizar comparaciones y visualizar fácilmente las diferencias entre los distintos resultados.

Fuente: Elaboración propia.

Respecto de la vinculación la- término indefinido, que oscila enboral, independiente o freelance oscila entre 5 y $37 \%$ en las distintas investigaciones, así como en el caso español, en especial en los periodistas digitales, quienes tienden a contar con varios empleos. En todos los casos, predomina el contrato a tre 40 y $70 \%$.

Ahora bien, la precariedad salarial lleva a los profesionales a contar con un segundo empleo. Según Mellado y Parra (2008), 45 \% de los encuestados contaba con dos o más empleos, dato que se repite en Mellado, Parra y 
Barría (2009), donde $16.3 \%$ de los encuestados indicó tener dos empleos; $4.9 \%$, tres, y $1.1 \%$, más de tres.

Al igual que en España, en América Latina aún existen periodistas que ejercen la profesión sin contar con un título profesional, puesto que este no es un requisito de ingreso en algunas empresas. De ahí que Burgos y López (2010) señalen que en $40 \%$ de las ocasiones las empresas no exigen el título profesional como requisito para obtener el empleo. Lagos y Cabalín (2009), por ejemplo, encontraron que $81.2 \%$ de su muestra contaba con título profesional, mientras que Ayala (2009) con tan solo $22.22 \%$.

Otra investigación de interés es la de Gutiérrez (2010), investigación en la que a $40 \%$ de los encuestados les exigieron como requisito de ingreso ser profesional en el área, mientras que a otro $20 \%$ experiencia laboral. Sin embargo, en el panorama general, las empresas suelen dar mayor importancia a la experiencia en el área (Arroyave y Blanco, 2005; Toribio, 2011; Sánchez, 2013) o evalúan a sus futuros empleados a partir de sus habilidades profesionales (redacción, ortografía, expresión verbal y el manejo del inglés) y factores socioeconómicos (vivir cerca del empleo, la edad, tener auto, el género, los estudios de posgrado y el examen de oposición) (Sánchez, 2013).
Ubicar la experiencia laboral sobre la formación profesional podría ser la causa de que algunos profesionales no logren conseguir un empleo en su área de estudio. Según Mellado, Parra y Barría (2009, p. 15), "un grupo importante de los encuestados no posee estudios superiores de ningún tipo, y muchos otros provienen de distintas áreas del saber". No obstante, $76 \%$ de los profesionales se encuentra laborando en un área donde aplica sus conocimientos profesionales (Burgos y López, 2010; Gutiérrez, 2010), de ahí que Sánchez (2014) indique también que la mayoría de los encuestados trabaja en aquello para lo que fueron formados.

En síntesis, el panorama permite concluir que entre 25 y $30 \%$ de los profesionales en el área no realiza actividades relacionadas con su carrera, dato que corrobora Sánchez (2012 b).

Respecto de las falencias en su formación, los periodistas latinoamericanos coindicen en que la academia presenta problemas a la hora de traducir el conocimiento científico al campo de acción laboral (Lagos y Cabalín, 2009). Para referirse al tema, Sánchez (2012b) delimita tres problemas concretos en la formación del profesional en periodismo/ comunicación: 
1. La nula vinculación entre la teoría y la práctica.

2. La semejanza entre planes de estudio, los cuales no parten de un diagnóstico de problemas y necesidades que contemple las condiciones económicas, sociopolíticas, ideológicas y culturales de la comunidad o región donde se erigen las instituciones de educación superior (IES) que ofertan la carrera de comunicación. También se debe considerar el posible campo laboral del egresado y determinar sus características. Estos aspectos permiten fundamentar una correspondencia entre lo que se necesita en la comunidad y lo que se enseña, lo que se aprende y lo que se logra en el aula, así como su aplicación en la realidad (Díaz Barriga, 1990).

3. El diseño tradicionalista de los planes de estudio evidencia atraso, puesto que no contempla nuevas modalidades comunicativas y está desfasado con respecto al avance que tienen los medios (pp. 127-128).

Problemas de formación académica que Sepúlveda (2002) ve reflejados en el "comunicador de hoy", cuando se refiere a este como un profesional 'tipo 'light', que aunque amigo o simpatizador de lo frugal e inmediato, en primera instancia, no lo inhibe de buscar profundidad al pensar" (p. 6).

Por su parte, Gutiérrez (2010) halla que $52 \%$ de los profesionales considera que a la formación académica le hacen falta escenarios de prácticas, conocimientos de gestión y habilidades empresariales (13\%), formación en un segundo idioma (13\%) y formación en tecnologías de la información y de la comunicación (TIC) (11\%).

Falencias que también son denunciadas por los empleadores, quienes encuentran en el profesional, principalmente, debilidades en "redacción, ortografía y reporteo, baja lectura... de conocimientos de actualidad, de capacidad reflexiva y de especialización, así como poco manejo del idioma inglés" (Délano, Niklander y Susacasa, 2007, p. 222).

Esta situación puede deberse a que con frecuencia los programas de periodismo/comunicación tienden a abarcar diversas ramas, sin llegar a profundizar en alguna de ellas (por lo menos esto es lo que manifiestan los profesionales). Por ejemplo, Rizo (2012) encuentra que las falencias de la formación académica 
se deben a la amplitud del programa (por lo que tiende a ser ambiguo), a la poca profundidad en la formación para trabajar en medios y al desligado vínculo entre la enseñanza y el ámbito profesional.

Ahora bien, Sánchez (2012b) propone que esta distancia entre empresa y universidad podría saldarse con estudios de posgrado en áreas corporativas (relaciones públicas, imagen, comunicación digital, ventas y mercadeo, entre otros). También con las prácticas profesionales, que suelen ser la principal fuente del primer empleo del profesional (Sánchez, 2013).

Otras investigaciones no referenciadas en la tabla 2 han abordado los periodistas y comunicadores desde elementos históricos y cualitativos. En este caso, Vega (1990) se orienta a elementos socioprofesionales de los periodistas con un estudio colectivo de sus vidas. En la historia identifica que la asociación de periodistas se presentó como la primera herramienta para luchar por la mejora de las condiciones laborales.

Por otro lado, Ruiz-Tagle (2005) busca describir el papel que desempeñan los comunicadores en los medios masivos de comunicación y cómo aplican la responsabilidad social inherente a su profesión en la promoción de la integración de personas con discapacidad. Este autor concluye, entre otras cosas, que "el comunicador y los medios de comunicación social... pueden aportar al proceso de un cambio de actitud de la sociedad hacia las personas con discapacidad y otros grupos minoritarios, dejando atrás prejuicios y estigmatizaciones" (p. 97).

Y Venegas (2011) asume una postura cualitativa y analiza el perfil del comunicador, articulando las demandas del mercado, la oferta de la academia y las expectativas de los estudiantes; con estas tres miradas propone aspectos por considerar en la formación del futuro profesional en lo académico, personal y laboral.

En lo laboral destaca que, debido a la saturación del mercado, este profesional debe optar por estudios de posgrado que le permitan especializarse. Asimismo, debe saber trabajar de forma interdisciplinaria y buscar su inserción en todo tipo de organizaciones, teniendo la comunicación como eje articulador de los procesos en todo tipo de entidad que se comprenda a sí misma como un cuerpo articulado, que requiere la planeación estratégica de la comunicación para lograr sus metas. 
Tabla 3. Satisfacción laboral en América Latina

\begin{tabular}{|c|c|}
\hline Autor & Satisfacción \\
\hline Arroyave y Blanco (2010) & $\begin{array}{l}\text { Satisfacción: encanto por su profesión. } \\
\text { Insatisfacción: horarios interminables y extenuantes, ausencia de incentivos, imposibilidad de } \\
\text { seguirse formando académicamente, falta de políticas claras de remuneración, mala remuneración, } \\
\text { presiones, falta de autonomía y ambiente laboral altamente tensionante. }\end{array}$ \\
\hline Lagos y Cabalín (2009) & $\begin{array}{l}\text { Satisfacción: relación con los compañeros de trabajo ( } 66 \text { \% de la muestra manifestó sentirse muy } \\
\text { apoyado por estos). }\end{array}$ \\
\hline Gutiérrez (2010) & $\begin{array}{l}\text { Satisfacción: } 74 \text { \% está satisfecho con su carrera, mientars que } 76.2 \% \text { se siente orgulloso de su } \\
\text { profesión. } \\
\text { Insatisfacción: } 34 \text { \% está insatisfecho con sus ingresos. }\end{array}$ \\
\hline Lugo-Ortiz (2011) & Satisfacción: 63.1 \% se siente orgulloso de su profesión y del medio en el que trabaja. \\
\hline Mellado y Parra (2008) & $\begin{array}{l}\text { Satisfacción: } 51.6 \% \text { siente solo un regular nivel de satisfacción con la condición profesional del } \\
\text { periodismo. } \\
\text { Insatisfacción: } 41.6 \% \text { de los periodistas regionales no está satisfecho con lo que gana, no se } \\
\text { manifiesta orgulloso con el desarrollo de la profesión en la región ( } 45.6 \%) \text {. }\end{array}$ \\
\hline Rizo (2012) & Satisfacción: la mayoría de los encuestados afirma estar estudiando la carrera que siempre quiso. \\
\hline Vega y Borda (2013) & Satisfacción: 72 \% señaló contar con los recursos adecuados para desempeñar su trabajo. \\
\hline Toribio (2011) & Satisfacción: 57.69 \% considera que saldrá preparado para trabajar. \\
\hline Mellado-Ruiz y Lagos (2013) & $\begin{array}{l}\text { Insatisfacción: el salario genera insatisfacción, lo cual se relaciona con la desigualdad social que } \\
\text { existe en el país. Asimismo, el incumplimiento de las necesidades básicas de estabilidad y bienestar. }\end{array}$ \\
\hline Mellado et al. (2010) & $\begin{array}{l}\text { Satisfacción: los periodistas más conformes con el sector laboral en el que se desempeñan son los } \\
\text { que trabajan en medios ( } 66.7 \% \text { y en la empresa privada ( } 53.2 \%) \text {. } \\
\text { Insatisfacción: cerca de } 70 \% \text { de quienes laboran en el sector educación y el sector público hubiera } \\
\text { preferido trabajar en los medios, la empresa privada o el sector público. Entre los periodistas } \\
\text { vinculados a organizaciones de la sociedad civil, productoras o consultoras, el descontento es mayor: } \\
8 \text { de cada } 10 \text { hubiera preferido trabajar fuera de dichos sectores laborales. }\end{array}$ \\
\hline
\end{tabular}

Fuente: Elaboración propia.

En la tabla 3 se condensan las referencias a la satisfacción laboral, concluyendo como principal causa de satisfacción e insatisfacción el salario y el amor por la profesión y el sentir que se trabaja en el campo de su interés, respectivamente.

\section{El caso colombiano}

Colombia no es diferente del panorama internacional en cuanto a la precariedad laboral e insatisfacción del profesional en periodismo y comunicación. Frente al panorama regional, la situación es similar a la presentada en México y Chile, con salarios que oscilan entre US\$400 y US\$800, por lo cual Colombia queda por debajo del promedio de América Latina y España que, según Gutiérrez (2010), es de US\$1033.

En adición a los bajos salarios, Manrique y Cardona (2003) 
encuentran que $89 \%$ de los periodistas del país laboran en condiciones precarias, debido al incumplimiento de las garantías laborales contempladas por ley, entre las que se encuentran no pagar cesantías (10\%), intereses de cesantías (15\%), vacaciones (12\%), pensión (11\%), caja de compensación familiar (15\%), ARP (8 \%) y EPS (5\%) y horas ex$\operatorname{tras}(87 \%)$.

Otra tendencia de precariedad laboral está en los contratos por arrendamiento o venta de cupos. En este caso, las empresas de medios no establecen un salario básico al profesional, sino que le arriendan un espacio para su producción independiente o le ofrecen cupos publicitarios para que él los comercialice y de ahí obtenga su salario. Lo que implica que, además de sus labores de producción mediática, vea comprometido su tiempo e intereses con la venta y el marketing publicitario (taba 4).

Tabla 4. Investigaciones desarrolladas en Colombia

\begin{tabular}{|c|c|c|c|c|}
\hline Autor & Ciudad & $\begin{array}{c}\text { Población de } \\
\text { estudio }\end{array}$ & Valor del salario & Tipo de contratación \\
\hline $\begin{array}{l}\text { Manrique } \\
\text { y Cardona } \\
\text { (2003) }\end{array}$ & $\begin{array}{l}\text { Bogotá, Cali, } \\
\text { Medellín, } \\
\text { Barranquilla, } \\
\text { Cartagena, } \\
\text { Pereira, } \\
\text { Bucaramanga } \\
\text { y Cúcuta }\end{array}$ & $\begin{array}{l}309 \text { periodistas de } \\
10 \text { medios de todo } \\
\text { el país }\end{array}$ & US\$531 aproximadamente & $\begin{array}{l}51 \% \text { indefinido } \\
21 \% \text { término fijo } \\
15 \% \text { arrendamiento o venta de cupo } \\
12 \% \text { por prestación de servicio } \\
2 \% \text { freelance }\end{array}$ \\
\hline $\begin{array}{l}\text { Barrios y } \\
\text { Arroyave } \\
\text { (2007) }\end{array}$ & $\begin{array}{l}\text { Bogotá, } \\
\text { Medellín, Cali, } \\
\text { Barranquilla y } \\
\text { Cartagena }\end{array}$ & $\begin{array}{l}5 \text { grupos de discusión } \\
\text { integrados por } 5 \text { a } \\
12 \text { periodistas de los } \\
\text { distintos medios }\end{array}$ & $\begin{array}{l}\text { Precaria. Siendo menor en } \\
\text { radio, y mayor en televisión } \\
\text { y prensa. }\end{array}$ & No especifica \\
\hline $\begin{array}{l}\text { Iriarte } \\
\text { (2005) }\end{array}$ & Barranquilla & $\begin{array}{l}25 \text { periodistas de } \\
\text { radio y televisión }\end{array}$ & $\begin{array}{l}\text { US\$ } \$ 00.84 \\
\text { aproximadamente }\end{array}$ & № especifica \\
\hline $\begin{array}{l}\text { Gutiérrez } \\
\text { et al. } \\
\text { (2010) }\end{array}$ & $\begin{array}{l}11 \text { principales } \\
\text { ciudades }\end{array}$ & 185 periodistas & $\begin{array}{l}34 \% \text { salario entre } \\
\text { US\$ } \$ 400.84 \text { y US\$801.68 } \\
27.6 \% \text { entre US\$200.42 y } \\
\text { US\$400.84 } \\
\text { Algunos no cuentan con } \\
\text { salario fiio, sino con cupos } \\
\text { publicitarios que deben } \\
\text { vender }\end{array}$ & $\begin{array}{l}\text { (No se indican valores) } \\
\text { Presencia de contratos: } \\
\text { indefinidos, } \\
\text { a término fijo, } \\
\text { por prestación de servicios }\end{array}$ \\
\hline $\begin{array}{l}\text { Salazary } \\
\text { Sepúlveda } \\
\text { (2011) }\end{array}$ & Colombia & № especifica & US\$481.86 & № especifica \\
\hline
\end{tabular}

Fuente: Elaboración propia. 
Frente a los requisitos para obtener el empleo, Gutiérrez et al. (2010) afirman que a $69.7 \%$ de sus encuestados se les exigió el título profesional como principal requisito de ingreso, junto con la experiencia previa (53\%) y dominio de las nuevas tecnologías (44.8\%).

Al igual que en los demás países de América Latina, los periodistas/comunicadores colombianos se sienten insatisfechos con su salario, la ausencia de seguridad social y contar con horarios extenuantes (Barrios y Arroyave, 2007; Gutiérrez et al., 2010). Se repite en este contexto la presencia de denuncias frente a las exigencias institucionales que privilegian el interés económico, comercial o político antes que el ejercicio informativo (Barrios y Arroyave, 2007; Iriarte, 2005). Ahora bien, la mayor satisfacción del profesional en este campo se relaciona con el sentimiento de que se realiza una labor importante para la sociedad (Gutiérrez et al., 2010).

Respecto de la formación académica, se repite el panorama latinoamericano. Con la distancia existente entre la academia y la vida laboral, se indica que el egresado vive un choque al salir a buscar un trabajo, puesto que la precariedad del mercado lo obliga a alternar las labores propias de su profesión con labores de mercadeo para poder acceder a un salario en algunos medios (Barrios y Arroyave, 2007).

Dificultad ante la cual los periodistas ven los estudios de posgrado como la forma ideal de mejorar el nivel de formación y enfocarse en aquello que demanda el mercado. Gutiérrez et al. (2010) insisten en la importancia de las universidades a la hora de identificar las demandas del mercado y asegurar que el perfil del estudiante sea coherente con el entorno en las competencias y habilidades requeridas.

Se reconoce también la necesidad de generar programas de formación continua de forma virtual para responder a las necesidades de aquellos profesionales que no cuentan con el tiempo o el dinero para acceder a la educación presencial tradicional, debido a sus horarios laborales (Gutiérrez et al., 2010).

Además de los aspectos económicos, se encuentran las dificultades inherentes al ejercicio en zonas de conflicto armado y corrupción. Barrios y Arroyave (2007) aseguran que las mayores presiones de los periodistas y comunicadores provienen de grupos al margen de la ley, que amenazas contra sus vidas por 
efectuar denuncias ante la corrupción. Gutiérrez et al. (2010) informan que los periodistas se han visto afectados por factores "económicos $19 \%$, políticos $15 \%$, sociales $11 \%$ o del conflicto armado $16 \% "$ (p. 8).

Iriarte (2005) manifiesta la denuncia de sus entrevistados frente a la corrupción en alcaldías, donde se presentan altos rubros asignados a gastos de contratación para "comunicaciones"; los políticos pagan a determinada persona o empresa por un servicio y posteriormente cobran una "comisión" por haber otorgado el contrato o cupo publicitario, lo cual podría implicar que se comprometa la ética e imparcialidad de la labor periodística.

\section{La situación laboral del comunicador social en Cúcuta}

En el ámbito local, la Universidad Francisco de Paula Santander-Sede Cúcuta se dio a la tarea de conocer la situación laboral del comunicador social en las diferentes empresas de la ciudad. Para tal cometido, estas se segmentaron en privadas de medios de comunicación, organizaciones no gubernamentales, instituciones públicas y privadas. Estas investigaciones consisten en estudios descriptivos, cuyo instrumento de recolección de información es la encuesta. En una primera etapa del proyecto, Estupiñán, Méndez y Vargas (2013) abordan la situación laboral del comunicador social en los medios privados de comunicación de la ciudad, identificando 41 comunicadores sociales que laboraban en 14 empresas de medios, entre ellas 5 medios impresos, 5 radiales, 3 televisivos y 1 agencia de publicidad durante el segundo semestre de 2012.

En la investigación solo se tienen en cuenta profesionales titulados. Se halla, entre otras cosas, que laboraban aproximadamente 44 horas semanales y contaban en su mayoría con una experiencia laboral alrededor de 1 a 3 años.

La precariedad laboral se ve aquí expresada en el bajo salario de los periodistas: \$1 000000 (US\$399) mensuales aproximadamente. Salario por debajo del promedio nacional de US $\$ 481.86$, indicado por Salazar y Sepúlveda (2011), y por debajo también del promedio latinoamericano de US $\$ 1033$ mensuales, señalado por Gutiérrez (2010).

Condición que lleva a estos profesionales a contar con dos o más empleos. En este caso, $26.82 \%$ de los encuestados indicó contar con dos 
empleos, en su mayoría relacionados con el área de la comunicación, empleo al que dedican aproximadamente 12 horas por semana, lo que se suma a un empleo principal que suele ser de tiempo completo.

También salió a relucir el débil vínculo establecido entre universidad-empresa. Los profesionales indicaron que la academia no estaba teniendo en cuenta las necesidades cambiantes del entorno en la formación de los periodistas y comunicadores de la región.

Respecto de los tipos de contratación, al igual que el promedio nacional e internacional, predominan los contratos a término indefinido (56\%), seguidos por los contratos por prestación de servicios (24\%) y a término fijo (14\%), mientras que $4 \%$ de los profesionales labora como independiente o freelance.

Como puede verse, la situación planteada por Manrique y Cardona (2003) en la panorámica nacional no ha cambiado mucho en los últimos 10 años. En el caso cucuteño, se presentan faltas al Código Sustantivo del Trabajo en cuanto algunos de los profesionales con contratos a término fijo e indefinido deben cancelar de forma independiente sus prestaciones sociales (EPS, pensión, ARP), además de aquellos que cuentan con contratos por prestación de servicio sin dichas prestaciones, lo cual reduce ostensiblemente su salario.

En cuanto a la satisfacción laboral, $56.1 \%$ indicó sentirse insatisfecho y muy insatisfecho con la remuneración económica recibida; pero, al igual que en el contexto de España y América Latina, los periodistas cucuteños se sienten orgullosos de su profesión y satisfechos de sus relaciones entre compañeros y jefes de trabajo (90.24\% afirmó tener relaciones laborales gratas con su jefe).

Un segundo acercamiento al contexto cucuteño lo realizan Álvarez, Márquez y Mendoza (2013), pero, en esta ocasión, abordando los empleadores, para descubrir el perfil del comunicador social que requieren las empresas de medios. Entre sus hallazgos se evidencian la precariedad laboral, pero también la marcada tendencia de reducir la labor del comunicador social a las labores periodísticas.

Una vez encuestados 19 gerentes y jefes de talento humano de las empresas privadas de medios de comunicación, Álvarez, Márquez y Mendoza (2013) concluyen que el comunicador social que demandan los medios de Cúcuta debe ser: 
Especialista en periodismo (Comunicador Periodista) con conocimientos en comunicación corporativa y comunicación para el cambio social, desempeñando las siguientes actividades.

Producción periodística: manejo de cámara de video, iluminación y control de radio, estratega de campañas radiales, productor de medios, reportero gráfico, presentador de televisión, redactor, reportero, investigador... (p. 80).

Aun cuando el periodista ejerce labores en la producción mediática, los gerentes de medios encuestados indicaron que también esperan que estos profesionales aporten al área de la comunicación corporativa como estratega de la comunicación en labores de "comunicación interna y externa, periodismo corporativo, relaciones públicas, manejo de identidad de la empresa, comunicación de marketing, difusión de las acciones de responsabilidad social empresarial, implementación y aprovechamiento de TIC” (p. 81).

Finalmente, se encuentra la investigación desarrollada por García (2014), con el propósito de conocer la situación laboral de los comunicadores en las organizaciones no gubernamentales (ONG) de Cúcuta. La tarea inicia con la identificación de las ONG presentes en la ciudad, en total 131, de las cuales solo 10 cumplen con los requisitos del estudio, que es contar o haber contado con un profesional en comunicación social o periodismo o un practicante que ejerza sus funciones. La investigación se desarrolla con 5 comunicadores sociales y 10 organizaciones.

Entre estos comunicadores, el salario promedio es $\$ 927160$ (US\$370), valor que no supera el salario de los periodistas mediáticos de la ciudad (Estupiñán, Méndez y Vargas, 2013). En este caso, los años de experiencia, el nivel de estudios y el cargo ocupado no generan una diferencia sustancial en el salario devengado.

La contratación es de $40 \%$ a término fijo, $20 \%$ a término indefinido y $40 \%$ por prestación de servicios, lo cual evidencia el incumplimiento del Código Sustantivo del Trabajo, si se contrasta con el hecho de que $80 \%$ de los comunicadores indicó que debe asumir el pago total de su seguridad social como trabajador independiente (EPS, pensión, ARP). A esto se suma que las ONG someten el salario del comunicador a la gestión de recursos; en este caso, si se desea un aumento, el compromiso estaría 
en la gestión por parte del profesional para el aumento de ese recurso (salario).

En cuanto a la satisfacción laboral, el salario representa una inconformidad para $80 \%$ de los encuestados. La satisfacción se encuentra en relación con su profesión, la labor que realizan, la relación con su jefe y la libertad para elegir su método de trabajo.

La posición de los empleadores frente a los profesionales con que cuentan es bastante satisfactoria. A diferencia de los empleadores mediáticos, los de ONG perciben al comunicador social como un agente de cambio y requieren de él un comportamiento ético, proactivo, con compromiso, iniciativa y recursividad.

\section{Conclusiones}

Planteado el panorama internacional, nacional y local, pareciera que la perspectiva del campo es desalentadora. Pero es preciso diferenciar el campo de estudio del ejercicio profesional, por lo que se diferenciarán estos aspectos.

Frente al campo de estudios de la profesión, se evidencia una amplia gama de investigaciones. En este caso, se abordaron aquellas que tocan aspectos laborales, aunque es alentador ver que también se han realizado —en menor medida-investigaciones sobre la libertad de prensa, el periodismo de guerra y otros aspectos de la vida del periodista y comunicador.

En cuanto a la metodología, la mayoría de las investigaciones asume un abordaje cuantitativo con la aplicación de encuestas; en muy pocas ocasiones el abordaje prefirió las entrevistas o grupos de discusión (Arroyave y Blanco, 2010; Barrios y Arroyave, 2007; Cantalapiedra, Coca y Bezunarte (s. f.); Délano, Niklander y Susacasa, 2007; Gutiérrez et al., 2010; Rivera, 2003; Ruiz-Tagle, 2005; Venegas, 2011; Ufarte, 2011).

Se presenta como potencialidad el campo de estudio del comunicador social, más allá de su accionar periodístico, en campos corporativos en entidades públicas y privadas, así como el estudio cualitativo de la profesión en general, para conocer nuevos aspectos sobre la vida cotidiana, la historia de los medios y las dificultades que se afrontan en un campo de acción, que es siempre cambiante.

Rivera (2003) señala que es necesario seguir investigando sobre oficinas de relaciones públicas, los ministerios de gobierno y entidades estatales, para contribuir a la formación 
de un especialista en comunicación y que las entidades logren articular en sus oficinas de comunicación no solo la producción tradicional de periodismo corporativo, sino que fusionen estas labores con las propias de la comunicación organizacional, como la planeación estratégica de la comunicación con todos sus públicos, el manejo de la imagen y la marca de la entidad.

Ahora bien, respecto del periodismo como profesión y campo laboral, la revisión permite concluir que en general los periodistas y comunicadores se encuentran en condiciones de empleo fuera de la ley que no permiten su desarrollo profesional ni su satisfacción laboral tanto por el salario devengado como por las presiones que reciben del medio para estar en sintonía con los interés políticos y económicos.

Esta situación lleva a que muchos cuenten con dos o más empleos, o se vea comprometido su accionar con la venta de cupos o pauta publicitaria. Iriarte (2005) critica fuertemente esta nueva arista en el trabajo del periodista:

Vender es un verbo clave en el oficio periodístico. En Colombia es cada vez más difícil ejercer esta profesión sin pisar el terreno de las ventas. Desde el director nacional de noticias de una cadena o el conductor del programa de más alto rating -que vende millones con una llamada telefónica - hasta el reportero raso que entra a engrosar las filas de esa misma cadena en una ciudad mediana. Todos tienen que vender (p. 5).

Esta circunstancia va en detrimento no solo del ejercicio ético y responsable, sino de la capacidad real del profesional de dedicar su espacio a dos labores, la periodística y la de mercadeo, lo cual indiscutiblemente tendrá un impacto sobre su producción.

Por otro lado, de manera positiva, algunos autores destacan que, aun cuando el campo periodístico en medios tradicionales se encuentra saturado, los nuevos escenarios de comunicación digital se presentan como una oportunidad laboral, así como las empresas que no están relacionadas con el sector de la comunicación y que empiezan a ver el papel corporativo del comunicador (Calvo, 2005).

A manera de recomendación y oportunidades de mejora para las universidades, los profesionales en 
ejercicio identificaron falencias en su proceso de formación académica. Entre lo que destaca la carencia de contenidos propios de la era digital y el ciberperiodismo (Calvo, 2005) y la falta de prácticas y el exceso de teoría (Farias y Gómez, 2011), entendida como una desconexión de la realidad.

Y es aquí donde se destaca la pertinencia de conocer el campo de acción del profesional en los análisis de cada plan de estudios de periodismo y comunicación, para asegurar su pertinencia y coherencia con las necesidades contextuales y, en ese sentido, asegurar que sus profesionales estén preparados para el mundo laboral y sus cambios constantes.

\section{Referencias bibliográficas}

Agencia Nacional de Evaluación de la Calidad y Acreditación (Aneca) (s. f.). Libro Blanco: títulos de grado en comunicación. Recuperado de http:// www.aneca.es/var/media/150336/libroblanco_comunicacion_def.pdf

Álvarez, K., Márquez, J. y Mendoza, J. (2013). Perfil del comunicador social que demanda las empresas de medios en la ciudad de Cúcuta (Tesis de grado, Universidad Francisco de Paula
Santander, San José de Cúcuta, Norte de Santander, Colombia).

Arroyave, J. y Blanco, I. (2010). Cómo perciben los periodistas su profesión: entre el agotamiento y la fascinación. Investigación \& Desarrollo, 13(2), 364389. Recuperado de http://rcientificas.uninorte.edu.co/index.php/investigacion/article/viewArticle/1004

Ayala Perdomo, J. C. (2009). Seguimiento laboral de egresados 2008. Licenciatura en Comunicación de la Facultad de Ciencias Políticas y Sociales de la UAEM. Espacios Públicos, 12(26), 315-328. Recuperado de http://www.redalyc.org/articulo. oa?id=67612145019

Barrios, M. y Arroyave, J. (2007). Perfil sociológico de la profesión del periodista en Colombia: diálogo íntimo con el ser humano detrás de las noticias. Diálogos de la Comunicación, 75. Recuperado de http://www. dialogosfelafacs.net/wp-content/ uploads/2012/01/75-revista-dialogosperfil-sociologico-del-periodista-.pdf Burgos Flores, B. y López Montes, K. (2010). La situación del mercado laboral de profesionistas. Revista de la Educación Superior, 39(156), 19-33. Recuperado de http://www. 
scielo.org.mx/scielo.php?pid=S0185$27602010000400002 \&$ script $=$ sci arttext\&tlng=pt

Calvo Bermejo, L. (2005). El informe sobre la situación laboral y profesional del periodista digital en Cataluña. Mediatika: Cuadernos de Medios de Comunicación, 11, 171-183. Recuperado de http://www.euskomedia.org/ PDFAnlt/mediatika/11/11171183.pdf

Cantalapiedra, M. J., Coca, C. y Bezunarte, O. (s. f.). La situación profesional y laboral de los periodistas vascos. Recuperado de http://www. ehu.eus/zer/hemeroteca/pdfs/zer0912-cantalapiedra.pdf

Chong, B. y De Santiago, A. (2006). Los egresados de la Carrera de Comunicación en el campo laboral. Buenaval, Revista de Investigación Social, 3, 32-47.

De la Quintana García, A. (s. f.). La situación de los becarios de periodismo en los medios de comunicación 2010. Recuperado de http://campus. usal.es/ comunicacion3punto0/comunicaciones/019.pdf

Délano, M., Niklander, K. y Susacasa, P. (2007). Los periodistas recién titulados y el mercado laboral. Calidad en la Educación, 27, 205-234. Recuperado de http://www.cned.cl/public/ secciones/seccionGeneral/noticias/ ppts/CSEConferencia01.pdf

Díaz Barriga, F., Lule, M. y Pacheco. D. (1990). Metodología de diseño curricular para educación superior. México: Trillas.

Estupiñán, E., Méndez, V. y Vargas, G. (2013). Situación laboral del comunicador social en las empresas privadas $y$ medios de comunicación en la ciudad de Cúcuta (Proyecto de grado, Universidad Francisco de Paula Santander, Cúcuta, Colombia).

Farias Batlle, P. y Gómez Aguilar, M. (2011). El estado de la profesión periodística y la crisis de los medios en España. Razón y Palabra, 77, 66. Recuperado de http://www.razonypalabra.org.mx/varia/77\%205a\%20parte/68_FariasGomez_V77.pdf

Federación Latinoamericana de Facultades de Comunicación Social (Felafacs) (2009). Informe Final del proyecto: mapa de los centros y programas de formación en Comunicación y Periodismo en América Latina y el Caribe. Recuperado de http://www.felafacs.org/wp-content/ uploads/2012/02/mapeo_com.pdf 
Fernández Areal, M. (2010). Una profesión titulada "Periodismo". Revista Latina de Comunicación Social, 65, 1-13. Recuperado de http:// www.revistalatinacs.org/10/art/879_ Vigo/01_MF_Areal.html

Ferrández-Ferrer, A. (2012). Sobre la experiencia laboral de los periodistas migrantes en un contexto de desregulación: entre la precariedad y la democratización del campo mediático. Comunicación y Sociedad, 25(2), 305330. Recuperado de http://dadun. unav.edu/bitstream/10171/27965/1/ Articulo12.pdf

García, A. (2014). La situación laboral del comunicador social en organizaciones no gubernamentales de la ciudad de Cúcuta N. S. (Anteproyecto de grado, Universidad Francisco de Paula Santander, Cúcuta, Colombia).

García-Ureta, I., Toral-Madariaga, G. y Murelaga-Ibarra, J. (2012). Comunicadores resonantes, comunicadores eficaces: flujo y credibilidad del comunicador. Revista Latina de Comunicación Social, 67, 99-124. Recuperado de http://www.revistalatinacs. org/067/art/949_UPV/05_Irene.html

Gómez Aguilar, M. (2009, 9-11 de diciembre). Análisis de la situación laboral/profesional en el periodismo desde una perspectiva de género. En Actas I Congreso Internacional Latino de Comunicación Social (p. 109). La Laguna, Tenerife: Sociedad Latina de Comunicación Social. Recuperado de http://www.revistalatinacs.org/09/ Sociedad/actas/109marisol.pdf

Gutiérrez Coba, L., Prada Penagos, R., Valderrama Valderrama, J. E., García Perdomo, V., Guzmán de Reyes, A. y Forero Gutiérrez, A. (2010). Las condiciones laborales y la satisfacción de los periodistas colombianos. Investigación y Desarrollo: Revista del Centro de Investigaciones en Desarrollo Humano, 18(1), 24-43.

Gutiérrez, F. (2010, 13 de noviembre). Situación laboral del comunicador social (diagnóstico). En VI FELAFACSNCA. San Francisco. Recuperado de http://es.scribd.com/doc/48245518/ Situacion-Laboral-del-ComunicadorSocial-Diagnostico\#scribd

Guzmán Gómez, C. (1994). Entre el deseo y la oportunidad: los estudiantes de la UNAM frente al mercado de trabajo. México: Universidad Nacional Autonoma de México.

Iriarte, P. (2005). Pauta oficial y libertad de prensa en Barranquilla, 
2004-2005: estudio piloto. Fundación para la Libertad de Prensa. Recuperado de http://flip.org.co/resources/ documents/8dc1264252685d435fb3 67ba309ed1b8.pdf

Lagos, C. y Cabalín, C. (2009). Condiciones profesionales del ejercicio del periodismo y de la libertad de expresión en los principales medios de comunicación de la región metropolitana. Santiago de Chile: ICEI.

López Hidalgo, A. (2005). El periodista en su soledad: de cómo la precariedad en el trabajo condiciona la ética y la independencia del profesional, y otras respuestas sin pregunta. Sevilla: Comunicacion Social.

Lugo-Ortiz, L. (2011). Valores y motivaciones profesionales: los periodistas en Puerto Rico en la era digital. Estudios sobre el Mensaje Periodístico, 17(2), 349-364. Recuperado de http:// revistas.ucm.es/index.php/ESMP/article/view/38119/36871

Manrique, A. y Cardona, I. (2003). Situación laboral de los periodistas en Colombia. Informe de la investigación. Bogotá: Antropos (Cátedra Konrad Adenauer de Comunicación y Democracia).
Martínez Mendoza, S., Matus López, J. y Villar Pinto, H. A. (2009). La condición laboral del periodista en Chiapas. Revista Latina de Comunicación Social, 64, 37. Recuperado de http://www.revistalatinacs.org/09/ art/37_836_27_Chiapas/Martinez_ et_al.html

Mellado Ruiz, C. (2009). Orígenes, evolución y desencuentros en la investigación sobre el periodista latinoamericano. Innovar: Revista de Ciencias Administrativas y Sociales, 19(33), 7-17.

Mellado Ruiz, C. y Parra, E. (2008). Indicadores de identidad y perfil del periodista regional en Chile. Opción, 24(55), 145-167. Recuperado de http://200.74.222.178/index.php/ opcion/article/view/6429/6417

Mellado Ruiz, C., Parra, E. y Barría, S. (2009). Mercado laboral y ejercicio del periodismo en la región del BíoBío. Concepción (Chile). Santiago de Chile: Universidad de Concepción.

Mellado Ruiz, C., Salinas, P., Del Valle, C. y González, G. (2010). Estudio comparativo de cuatro regiones: mercado laboral y perfil del periodista. Cuadernos de Información, 26, 45-64. Recuperado de 
https://repositorio.uc.cl/bitstream/ handle/11534/4363/000549185. pdf? sequence $=1 \&$ isAllowed $=y$

Mellado Ruiz, C. y Lagos, C. (2013). Características y factores condicionantes de la situación salarial de los periodistas en Chile. Palabra Clave, 16(2), 520-540. Recuperado de http:// www.scielo.org.co/pdf/pacla/v16n2/ v16n2a11.pdf

Rivera Fernández, V. A. (2003). Funciones del comunicador social en una organización estatal (Tesis de grado, Universidad Nacional Mayor de San Marcos, Lima, Perú). Recuperado de http://cybertesis.unmsm.edu.pe/bitstream/cybertesis/401/1/rivera_fv.pdf Rizo, M. (2012). Imaginarios sobre la comunicación. Algunas certezas y muchas incertidumbres en torno a los estudios de comunicación, hoy. Bellaterra: Institut de la Comunicació, Universitat Autònoma de Barcelona. Recuperado de http://incom.uab.cat/ download/eBook_2_InComUAB_ MRizo.pdf

Ruiz-Tagle Molina, J. M. (2005). Análisis, desde una perspectiva cultural, del rol y la responsabilidad del comunicador social en el proceso de integración plena de las personas con discapacidad
(Tesis de grado, Universidad Austral de Chile, Valdivia, Chile). Recuperado de http://cybertesis.uach.cl/tesis/ uach/2005/ffr934a/doc/ffr934a.pdf

Sabés Turmo, F. y Verón Lassa, J. J. (2012). Universidad y empresa ante la doble crisis del periodismo tradicional: propuestas y reflexiones sobre la modificación sustancial del escenario periodístico. El clúster periodístico. adComunica, 4, 151-170. Recuperado de http://www.adcomunicarevista.com/ojs/index.php/adcomunica/ article/view/74

Salazar Gómez, M. y Sepúlveda, R. (2011). Perspectivas y proyección profesional de la comunicación social. Signo y Pensamiento, 31(59), 194-209. Recuperado de http://www.redalyc. org/articulo.oa?id=86022458014

Sánchez Olavarría, C. (2012a). Movilidad profesional y generacional del comunicador de la Universidad del Altiplano. Revista Electrónica de Investigación Educativa, 14(2), 150165. Recuperado de http://www.scielo.org.mx/scielo.php?pid=S1607$40412012000200011 \&$ script $=$ sci arttext

Sánchez Olayarría, C. (2012b). La práctica profesional del comunicador 
de la Universidad del Altiplano: un panorama de su trayectoria. Perfiles Educativos, 34(137), 119-144. Recuperado de http://www.scielo.org. $\mathrm{mx} /$ scielo.php? pid=S0185$26982012000300008 \&$ script $=$ sci_ $\operatorname{arttext\& tlng}=\mathrm{pt}$

Sánchez Olavarría, C. (2013). La inserción laboral de los comunicadores de la Universidad del Altiplano. Revista de la Educación Superior, 42(165), 105-123. Recuperado de http://www. scielo.org.mx/scielo.php?pid=S018527602013000100006\&script=sci_arttext

Sánchez, C. (2014). Los egresados de comunicación y el mercado laboral: un estudio de trayectorias profesionales. Revista Iberoamericana de Educación Superior, 5(13), 40-54. Recuperado de http://www. scielo.org.mx/scielo.php?pid=S2007$28722014000200003 \&$ script $=$ sci_

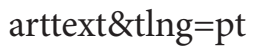

Sepúlveda, H. (2002). Contrario al maná, el comunicador no baja del cielo: nacimiento, construcción o reinvención del profesional en Puerto Rico. Ciberlegenda, 7. Recuperado de http://www.uff.br/ciberlegenda/ojs/index.php/revista/article/ view/328/209
Sierra Sánchez, J. (2012). Periodistas del medio radiofónico en Barcelona: tendencias, formación y situación laboral. Zer: Revista de estudios de comunicación= Komunikazio ikasketen aldizkaria, 17(32), 73-87. Recuperado dehttp://www.ehu.eus/zer/hemeroteca/pdfs/zer32-04-sierra.pdf

Tejedor, S. (2005, 20-21 de enero). El periodista digital en España. En Congreso Nacional de Periodismo Digital, Huesca.

Toribio Tavares, P. (2011). Expectativas profesionales de los estudiantes de Comunicación Social de Santo Domingo, República Dominicana (Tesis pregrado, Pontificia Universidad Católica Madre y Maestra, Santo Domingo, República Dominicana). Recuperado de http://com-pucmm.org/moodle/ file.php/1/Tesis/Ano_2011/Expectativas_profesionales_de_los_estudiantes_de_Comunicacion_Social_ de_Santo.pdf

Ufarte Ruiz, M. J. (2011). El periodista acosado: entre la precariedad laboral y el mobbing. Un estudio de caso: la precariedad de los periodistas almerienses en la prensa escrita (Tesis de doctorado. Universidad de Sevilla, Sevilla, España). 
Universidad Autónoma Metropolita- transición del periodismo en Costa na, Casa Abierta al Tiempo y Sistema Rica (1950-1960). Revista de Ciencias de Información de Estudiantes Egre- Sociales, 47(47-50), 27-40. Recuperasados y Empleadores (2010, noviem- do de http://163.178.170.74/wp-conbre). Resultados de la encuesta aplica- tent/revistas/47/vega.pdf da a egresados de la Licenciatura en Comunicación Social. Recuperado de http://www.uam.mx/egresados/estudios/acreditacionlicenciatura/xoc/ Plan_64_Licenciatura_en_Comunicacion_Social_XOC_CSH_2010.pdf

Vega Jiménez, P. (1990). Los periodistas costarricenses en una época de transición del periodismo en Costa Rica (1950-1960). Revista de Ciencias Sociales, 47(47-50), 27-40.

Vega, V. y Borda, A. (2013). Los derechos de los periodistas. Percepciones en el lugar de trabajo. Revista Punto Cero, 18(27), 39-44.

Venegas Linguithy, Y. (2001). Nuevo perfil del comunicador social en el Perú de cara a los desafíos del nuevo milenio. Recuperado de http:// www.calandria.org.pe/rec_descarga. php?id_rec=218

Vega Jiménez, P. (1990). Los periodistas costarricenses en una época de 